\title{
Age Is Associated with Reduced Sharp-Wave Ripple Frequency and Altered Patterns of Neuronal Variability
}

\author{
Jean-Paul L. Wiegand, ${ }^{1,2}$ Daniel T. Gray, ${ }^{1,2}$ Lesley A. Schimanski, ${ }^{1,2}$ Peter Lipa, ${ }^{1,2}$ C. A. Barnes, ${ }^{1,2,3,4}$ \\ and Stephen L. Cowen ${ }^{1,2,3}$ \\ ${ }^{1}$ Evelyn F. McKnight Brain Institute, University of Arizona, Tucson, Arizona 85724, 2Division of Neural System, Memory \& Aging, University of Arizona, \\ Tucson, Arizona 85724, ${ }^{3}$ Department of Psychology, University of Arizona, Tucson, Arizona 85721, and ${ }^{4}$ Departments of Neurology and Neuroscience, \\ University of Arizona, Tucson, Arizona 85724
}

\begin{abstract}
Spatial and episodic memory performance declines with age, and the neural basis for this decline is not well understood. Sharp-wave ripples are brief $(\sim 70 \mathrm{~ms})$ high-frequency oscillatory events generated in the hippocampus and are associated with the consolidation of spatial memories. Given the connection between ripple oscillations and memory consolidation, we investigated whether the structure of ripple oscillations and ripple-triggered patterns of single-unit activity are altered in aged rats. Local field and single-unit activity surrounding sharp-wave ripple events were examined in the CA1 region of the hippocampus of old $(n=5)$ and young $(n=6)$ F344 rats during periods of rest preceding and following performance on a place-dependent eyeblink-conditioning task. Neural responses in aged rats differed from responses in young rats in several ways. First, compared with young rats, the rate of ripple occurrence (ripple density) is reduced in aged rats during postbehavior rest. Second, mean ripple frequency during prebehavior and postbehavior rest is lower in aged animals (aged: $132 \mathrm{~Hz}$; young: $146 \mathrm{~Hz}$ ). Third, single neurons in aged animals responded more consistently from ripple to ripple. Fourth, variability in interspike intervals was greater in aged rats. Finally, neurons were tuned to a narrower range of phases of the ripple oscillation relative to young animals. Together, these results suggest that the CA1 network in aged animals has a reduced "vocabulary" of available representational states.
\end{abstract}

Key words: consolidation; Fano factor; reactivation; senescence; spike-phase coupling

\section{Significance Statement}

The hippocampus is a structure that is critical for the formation of episodic memories. Sharp-wave ripple events generated in the hippocampus have been implicated in memory consolidation processes critical to memory stabilization. We examine here whether these ripple oscillations are altered over the course of the life span, which could contribute to hippocampus-dependent memory deficits that occur during aging. This experiment used young and aged memory-impaired rats to examine age-related changes in ripple architecture, ripple-triggered spike variance, and spike-phase coherence. We found that there are, indeed, significant changes in characteristics of ripples in older animals that could impact consolidation processes and memory stabilization in the aged brain.

\section{Introduction}

Normal aging is associated with a reduced capacity to consolidate and recall episodic memories (e.g., Pace-Schott and Spencer, 2015), and the neuronal basis for this decline is unknown. The

\footnotetext{
Received Aug. 14, 2015; revised April 4, 2016; accepted April 6, 2016.

Author contributions: L.A.S. and C.A.B. designed research; L.A.S. performed research; J.-P.L.W., D.T.G., P.L., and

S.L.C. analyzed data; J.-P.L.W., D.T.G., C.A.B., and S.L.C. wrote the paper.

This work was supported by the McKnight Brain Research Foundation and National Institutes of Health Grants R37 AG012609 and R01 AG003376.

The authors declare no competing financial interests.

Correspondence should be addressed to Dr. Stephen L. Cowen, University of Arizona, Life Sciences North, 1501 North Campbell Avenue, Room 347, Tucson, AZ 85724-5115. E-mail: scowen@email.arizona.edu.

DOI:10.1523/JNEUROSCI.3069-15.2016

Copyright $\odot 2016$ the authors $\quad 0270-6474 / 16 / 365650-11 \$ 15.00 / 0$
}

consolidation of episodic memory is believed to depend on the precise coordination of networks of neurons in the hippocampus and neocortex. The sharp-wave ripple oscillation (O'Keefe and Nadel, 1978; Buzsáki et al., 1992; Csicsvari et al., 1999) represents a key component of this coordination as hippocampal and cortical neurons have been shown to preferentially communicate during these events (Wierzynski et al., 2009). Ripples are traditionally defined as high-frequency $(140-240 \mathrm{~Hz})$ and brief (30$120 \mathrm{~ms}$ ) oscillatory events (Buzsáki et al., 1992) generated in the hippocampus that impact neuronal activity in cortical (Wierzynski et al., 2009) and subcortical (Pennartz et al., 2004) structures. Neuronal activity during ripples recapitulates segments of previous waking experience during subsequent rest (Kudrimoti et al., 1999; O’Neill et al., 2008). A causal relationship between sharp- 
wave ripples and memory consolidation is suggested by the observation that electrical disruption of ripples in rats during rest reduces performance on subsequent memory-recall tests (Girardeau et al., 2009, 2014; Ego-Stengel and Wilson, 2010; Nokia et al., 2010). Such observations lend support to theories suggesting that ripples are an important component of a wider corticohippocampal and striatal-hippocampal network involved in the systems-level consolidation of memory (Marr, 1971; McClelland et al., 1995).

Despite the importance of sharp-wave ripples in memory stabilization, little is known regarding how ripples change during the course of normal aging. Results from studies using hippocampal slices indicate that CA1 single-unit activity is delayed relative to ripple onset in aged animals (Kanak et al., 2013). There is also evidence that CA1 principal neurons in aged animals have increased burst firing (Smith et al., 2000), although this study did not confine its analysis exclusively to ripple events. Finally, while work by Gerrard et al. (2001) has demonstrated that both aged and young animals show memory trace reactivation, the fidelity with which temporal sequences are reactivated is reduced in aged animals (Gerrard et al., 2008). It is unknown, however, how features of the individual ripple oscillation or the interactions between ripples and single-unit activity change with age. Indeed, any change in ripple frequency or spike-phase synchrony could have implications for the efficacy of spike-timing-dependent plasticity (Bi and Poo, 1998). Increasing the temporal delay between presynaptic and postsynaptic activation would, according to the spike-timing-dependent plasticity (STDP) curve, cause exponential decay in synaptic strength and have cumulative effects over the course of sleep, ultimately affecting memory consolidation processes. Thus, this study investigates how these properties are altered in aging during periods of rest that precede and follow performance on a place-dependent eyeblink-conditioning task (Schimanski et al., 2013).

\section{Materials and Methods}

Subjects and behavioral pretraining. Data were analyzed from 6 young adult (9-12 months) and 5 old (25-28 months) male Fischer-344 rats that were obtained from the National Institute on Aging colony at Charles River. Rats were kept on a 12:12 h reversed light cycle and housed individually. All experiments were performed as described by Schimanski et al. (2013), following the guidelines of the United States National Institutes of Health Guide for the care and use of laboratory animals using protocols approved by the University of Arizona Institutional Animal Care and Use Committee.

Before behavioral or electrophysiological experiments, the Morris swim task was administered over four consecutive days to assess motor ability, vision, and spatial learning (Morris, 1984), as described in full by Barnes et al. (1996). Rats then underwent food restriction to $85 \%$ of free-feeding body weight and were pretrained on a shuttle task on a linear maze for food reinforcement until reaching 80 laps within $45 \mathrm{~min}$. Once physiological experiments began, animals were exposed to the spatial trace eyeblink task (described below). As reported by Schimanski et al. (2013), aged animals exhibited significant deficits in the spatial version of the water maze task relative to young animals but performed no differently than young rats on the eyeblink task.

Surgical and electrophysiological recording procedures. All rats received eyelid wire implantations for monitoring of spatial eyeblink conditioning behavior as well as a chronic microdrive or "hyperdrive" holding 12 independently adjustable tetrodes (Wilson and McNaughton, 1993). Before surgery, rats began antibiotic treatments (either 10 day ampicillin cycle or 5 day sulfamethoxazole and trimethoprim oral suspension cycle). On the day of surgery, rats were anesthetized using $1.0 \%-2.0 \%$ isoflurane in oxygen (flow rate $1.5 \mathrm{~L} / \mathrm{min}$ ) and placed into a stereotaxic apparatus. The hyperdrive was centered over a right hemispheric crani- otomy made at $2.0 \mathrm{~mm}$ lateral and $3.8 \mathrm{~mm}$ posterior to bregma. Tetrodes were constructed of four twisted polyimide-coated nichrome wires (13 $\mu \mathrm{m}$ diameter) and were driven to an initial depth of $1 \mathrm{~mm}$ at surgery. Over the next $14 \mathrm{~d}$, tetrodes were lowered to optimally record extracellular spikes from CA1 pyramidal cells ( $\sim 2 \mathrm{~mm}$ from brain surface). Two additional tetrodes whose four wires had been shorted together acted as references and were placed in or near the corpus callosum and hippocampal fissure. A ground screw and all wires were secured to the skull using dental acrylic.

Neural signals were amplified through a unity-gain headstage and programmable amplifiers (Neuralynx). Electrophysiological signals were recorded by the Cheetah Data Acquisition System (Neuralynx). A $1 \mathrm{~ms}$ window was recorded surrounding each candidate action potential. Single-unit activity was digitized at $32 \mathrm{kHz}$, amplified 500-5000 times, and bandpass filtered between $600 \mathrm{~Hz}$ and $6 \mathrm{kHz}$. Local field activity was recorded from a subset of tetrodes, bandpass filtered from 0.5 to $600 \mathrm{~Hz}$, and sampled at $1830 \mathrm{~Hz}$. Video tracking data were obtained with an overhead CCD camera. Movement during rest was calculated by finding the first derivative of the tracking data acquired from the CCD camera and subsequently squaring and smoothing the result.

Pretraining and tetrode adjustment continued for $\sim 14 \mathrm{~d}$ after surgery until behavior improved and clear CA1 action potentials were observed on the majority of tetrodes. At least 30 recording sessions were acquired from 10 rats (6 young and 4 old). Data were also acquired from a fifth aged rat. This rat, however, became ill after $15 \mathrm{~d}$ of recording, and so only these sessions were acquired and analyzed from this animal.

Behavioral procedures. On day 1 of the spatial-eyeblink conditioning experiment, rats were taken to a dedicated room for calibration of the level of electrical current necessary to induce an eyeblink. The eyelid stimulus was a $100 \mathrm{~ms}, 100 \mathrm{~Hz}$ train of bipolar square pulses $5 \mathrm{~ms}$ long, delivered through the wires implanted in the right eyelid using a Master-8 from A.M.P.I. and stimulus isolator A365 from World Precision Instruments. Every day before the experiment, current was modulated to induce a complete eyeblink (typical range, 0.1-0.6 mA). After calibration of the eyeblink current, rats were brought to a dimly lit recording room containing a horseshoe-shaped track ( $85 \mathrm{~cm}$ diameter), a towel-lined clay flowerpot, and numerous visual cues (Schimanski et al., 2013). Rats were placed in the pot to rest quietly alone for a minimum of 30 min before and after the behavioral task (Fig. 1A). Rats ran 10 laps for food reward. Starting on lap 11, rats received a blink-inducing electrical stimulation at two locations: one in the clockwise and one in the counterclockwise direction. Stimulation was delivered with a probability of $50 \%$. Rats ran on the track for a maximum of 74 laps or until ceasing locomotion. The number of laps was controlled between young and aged rat pairs by allowing the young rats to run the same number of laps as their yoked aged pair. The two within-day recording sessions were separated by an average of $157.5 \pm 4.0 \mathrm{~min}$. This protocol was repeated for $31 \mathrm{~d}$.

Statistical analyses. Standard parametric tests, such as Student's $t$ tests and ANOVA, were used with an $\alpha$ of 0.05 (two-tailed), except when specified otherwise. For parametric statistical analysis of neuronal firing rates, data were log-transformed so that distributions would approach the normal distribution (Buzsáki and Mizuseki, 2014). In cases where such transformations did not yield approximately normal distributions, nonparametric tests, such as the two-tailed Wilcoxon rank sum tests, were used. Analysis of phase and coherence required the use of statistical tests designed for the analysis of circular data such as the Rayleigh $z$ test for evaluating nonuniformity of phase distributions (Fisher, 1995).

Identification of high-frequency events. To reduce the impact of highfrequency artifacts on the local field signal from action potentials (Ray and Maunsell, 2011), local field activity was first "despiked" by removing a $4 \mathrm{~ms}$ window of data around spikes measured on the same tetrode and replacing the absent data with a spline (Zanos et al., 2011). Signals were then bandpass filtered $(80-240 \mathrm{~Hz})$ and squared. A candidate highfrequency event was identified whether the squared power exceeded 5 SDs above the mean, lasted for at least $30 \mathrm{~ms}$, and had a peak frequency of at least $90 \mathrm{~Hz}$. Only events that occurred during immobility as measured by video tracking were included in these analyses. The time of event onset was determined by moving backward in time from the point of threshold 
A

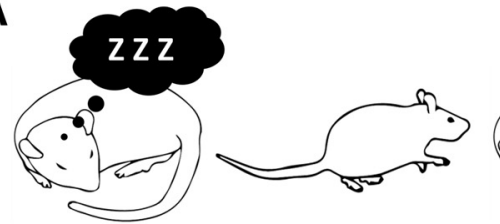

30 min PREbehavior rest $20-40 \mathrm{~min}$ behavior

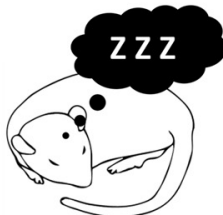

30 min POSTbehavior rest

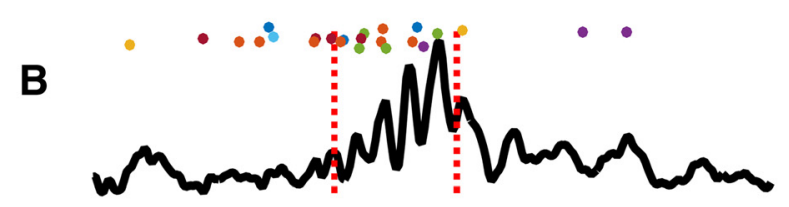

2 h break $2 \mathrm{~h}$ break

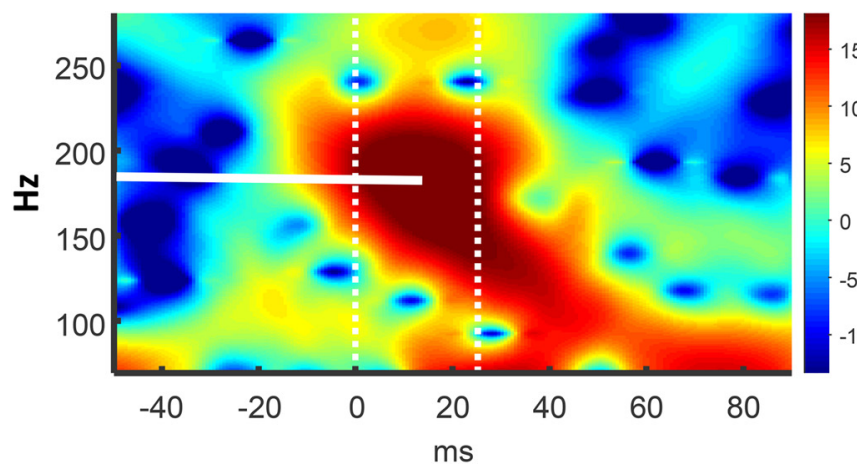

Z Z Z

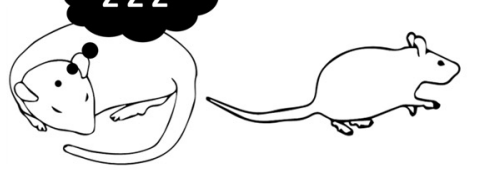

30 min PREbehavior rest
20-40 min behavior

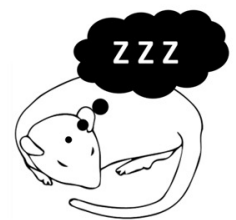

30 min POSTbehavior rest
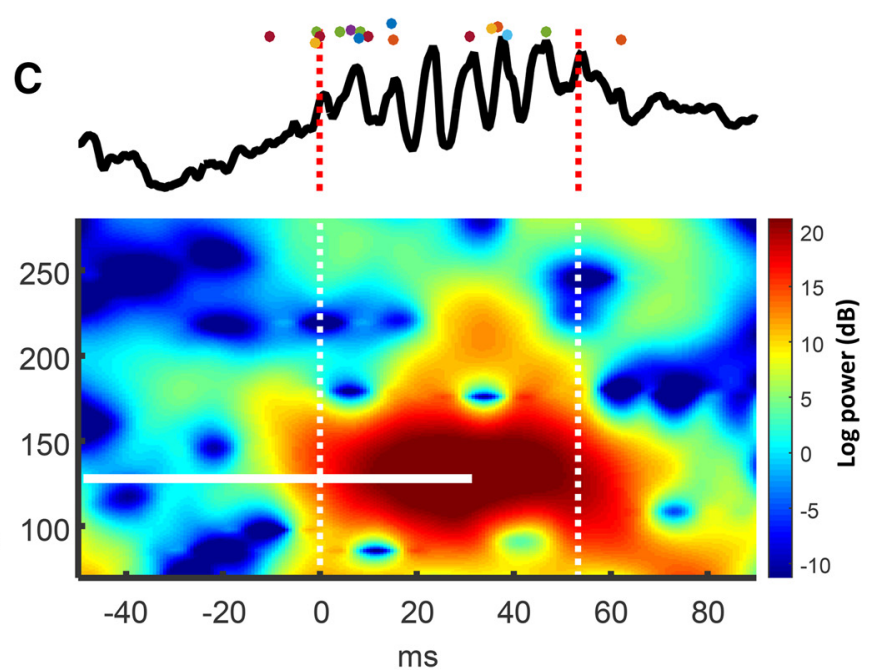

Figure 1. Behavioral paradigm and an example of a low- and high-frequency ripple oscillation recorded during rest. $\boldsymbol{A}$, Schematic of the behavioral paradigm. A daily recording session consisted of two behavioral epochs surrounded by a prebehavior and postbehavior rest period. $B$, Top, local field potential of a ripple (peak frequency: $187 \mathrm{~Hz}$ ). Colored dots indicate action potentials from simultaneously recorded neurons. Color represents neuron identity. Bottom, Fourier spectrogram. Zero on the $x$-axis indicates ripple onset. Peak frequency indicated by white horizontal line. $C$, A second example. Ripple peak frequency: $128 \mathrm{~Hz}$.

detection until power fell to 2 SDs above the mean. The same procedure was applied forward in time to determine event offset (for examples of detected ripple oscillations, see Figure 1). Peak frequency was determined by first constructing a spectrogram using a short-time Fourier transform across the extent of the ripple and then identifying the frequency with the highest power.

Depth of slow-wave modulation. Physiological quality of slow-wave sleep was determined by measuring the $\theta-\delta$ ratio as described by Wierzynski et al. (2009), with values $<1$ indicating slow-wave sleep. Local field activity was downsampled to $2 \mathrm{kHz}$, restricted to periods of a minimum of $1 \mathrm{~min}$ of immobility, and bandpass filtered in the $\theta(6-10 \mathrm{~Hz})$ and $\delta(0.5-2 \mathrm{~Hz})$ bands. Continuous root mean square values for each frequency band were smoothed over $1 \mathrm{~s}$ bins with a convolution filter. The $\theta-\delta$ ratio was then averaged over each recording session and each animal.

Normalizing peak deflection. Features of the ripple oscillation can vary as a function of depth in the CA1 cell layer (e.g., Sullivan et al., 2011). Because moveable tetrodes were used, the depth of a particular tetrode relative to the CA1 cell-body layer changed across days. A reliable indicator of the approximate distance from the electrode tip to the pyramidal cell layer of CA1 is the magnitude and direction of the deflection of the sharp-wave ripple event (Buzsáki et al., 1992). To ensure that crosssession and cross-animal measurements were acquired at similar depths relative to the layer, tetrodes were subsequently selected so that the distribution of these deflections was similar in aged and young animals. This was accomplished by quantifying the deflection for each ripple as the deviation from zero of the low-frequency bandpass-filtered $(7-15 \mathrm{~Hz})$ trace. Deflections were computed for each ripple and averaged across each session. This average was used as the within-session measure of deflection and was measured for each tetrode.

Analysis of single-unit data. Recorded spike events were sorted off line on the basis of the peak height, waveform energy, and principal components (KlustaKwik, author: K.D. Harris, Rutgers-Newark, Newark, NJ). These results were refined manually with custom-written software
(MClust, author: A.D. Redish, University of Minnesota, Minneapolis; Waveform Cutter, author: S.L. Cowen, University of Arizona, Tucson, AZ). No attempt was made to match cells from one daily session to the next. Consequently, the number of reported cells does not account for possible duplicate cells recorded across consecutive days, although a varying number of tetrodes were moved from day to day at the end of the second recording session (Schimanski et al., 2013).

Neurons were separated into putative principal cells and interneurons based on waveform shape, standardized autocorrelogram, and firing rate (Csicsvari et al., 1999; Barthó et al., 2004; Cowen and McNaughton, 2007). Neurons with a short-latency peak in the autocorrelogram $(<10$ $\mathrm{ms}$ ) and wide waveforms were classified as principal cells. Neurons with either narrow waveforms or a late peak in the autocorrelogram $(>100$ $\mathrm{ms}$ ) were classified as interneurons.

Cross-correlations (CCs) were computed using a bin size of $2 \mathrm{~ms}$ and a window of $100 \mathrm{~ms}$. A CC was considered to have a significant peak or trough if there was a significant difference $(t$ test, $p<0.01)$ between the vector of spike counts in the CC and the vector of spike counts in a CC created after shuffling the interspike intervals (ISIs) of the spike trains. To control for differences in baseline firing, mean CC activity between 70 and $100 \mathrm{~ms}$ on both sides of the peak of each CC was subtracted from each point on the CC so that values indicated the difference in the coincidence rate above or below this predetermined baseline.

Measurement of memory-trace reactivation. Reactivation of waking events during rest was calculated using the explained variance approach developed by Kudrimoti et al. (1999). Under this approach, reactivation is measured as the degree to which the pattern of cell-pair correlations measured during waking behavior is similar to the pattern observed during postbehavior rest. This approach involved first creating neuron $\times$ time matrices for rest and behavioral epochs (bin size: $20 \mathrm{~ms}$ ), and then using these matrices to determine cell-pair correlations during prebehavior rest, behavior, and postbehavior rest. Neuron $\times$ time matrices for rest were restricted to ripple intervals. The similarity between these 3 correlation-coefficient matrices was compared using the partial correla- 
A
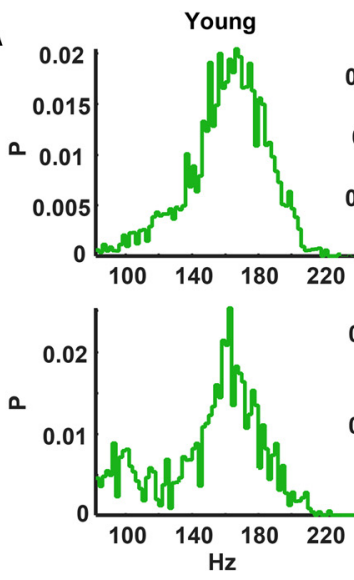
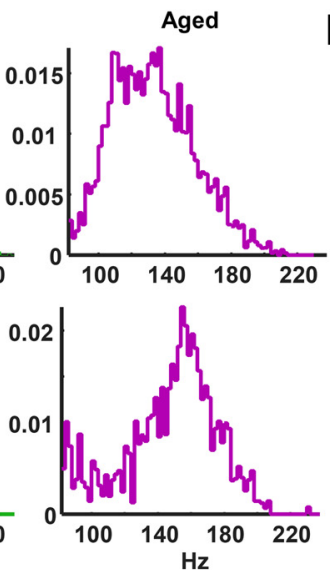

B

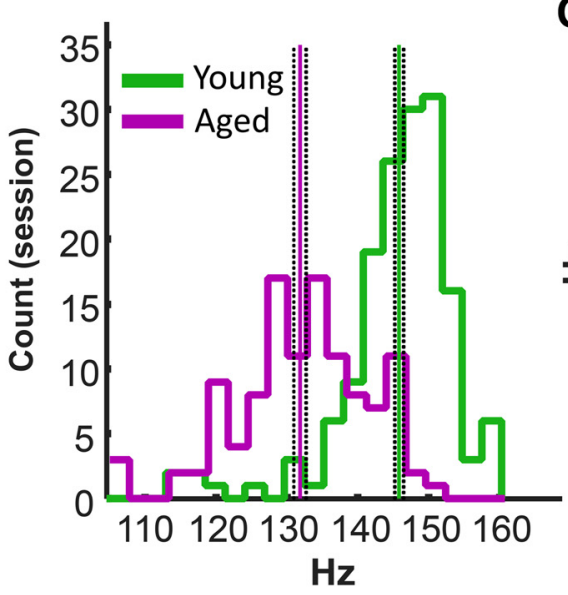

C

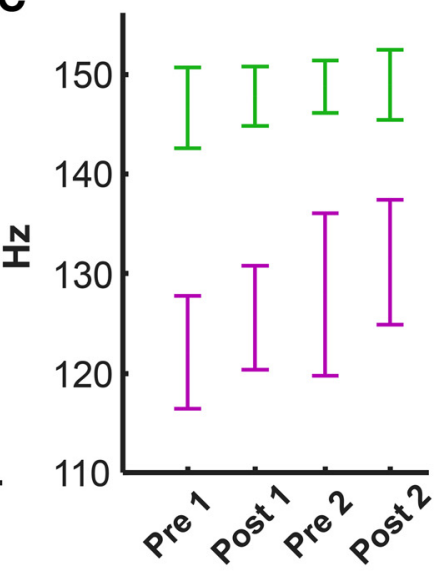

Figure 2. High-frequency oscillations are slower in aged rats. $A$, Example distributions of the peak oscillatory frequency of $90-240 \mathrm{~Hz}$ events acquired during rest from 4 representative recording sessions ( 2 young and 2 aged rats). In the majority of sessions, the distributions were unimodal ( $89 \%$ young, $79 \%$ aged, Hartigan's dip test, $\alpha=0.05$ ), although there were a few clear exceptions (bottom row). $\boldsymbol{B}$, The distribution of ripple frequencies across sessions (all 4 rest epochs within each session were combined). The mode frequency was $14 \mathrm{~Hz} \mathrm{lower} \mathrm{in} \mathrm{aged} \mathrm{animals}\left(p<10^{-6}\right.$, Rank Sum test, mean aged $=132 \mathrm{~Hz}$, mean young $=146 \mathrm{~Hz}$ ). Solid vertical lines indicate the mean. Dashed lines indicate SEM. $C$, Averaged by animal: A single mean oscillatory frequency was calculated for each rat ( $n=6$ young, $n=5$ aged) by averaging mode frequencies across sessions. Two-way ANOVA (age and rest epoch) revealed a significant effect of age $\left(p<10^{-5}\right)$ but not of epoch $(p=0.98)$.

tion coefficient between postbehavior rest and behavior, partialing out the contribution of prebehavior rest. This was compared with the partial correlation coefficient computed for prebehavior rest and behavior (re-

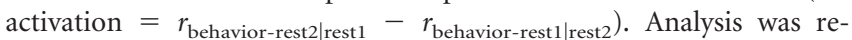
stricted to the first three epochs (rest1, behavior1, rest2).

\section{Results}

\section{Decreased oscillatory frequency of ripple oscillations in aged rats}

As we did not know a priori whether age-related changes in oscillatory frequencies might cross previously established frequency categories (Sullivan et al., 2011), we used a wide bandpass filter $(80-240 \mathrm{~Hz})$ to identify candidate high-frequency events. The distribution of ripple frequencies was determined by pooling all rest-associated ripple events during a single recording session (examples in Fig. $2 A$ ). The majority of these distributions were unimodal ( $89 \%$ young, $79 \%$ aged, Hartigan's dip test, $\alpha=0.05$ ), suggesting that, for most rest sessions, frequency varied on a continuum with no clear segregation of ripples into categories by frequency. Because these distributions were not Gaussian, the mode frequency was used as the measures of central tendency for each session. The distribution of these modal frequencies was compared in aged and young rats, revealing a clear segregation between age groups, with the mean of the distribution of modal frequencies being $132 \mathrm{~Hz}$ in aged and $146 \mathrm{~Hz}$ in young animals, a difference of $14 \mathrm{~Hz}$ (Fig. $2 B ; p<10^{-6}$, Rank Sum test, $n=156$ young sessions, $n=113$ aged sessions). The difference was also observed when averaged by animal (Fig. 2C; two-way ANOVA, factors: age and rest epoch, $n=6$ young, $n=5$ aged, effect of age $p<10^{-5}$, no effect of rest epoch was observed, $\left.p=0.98\right)$. In addition, ripple frequency distributions for young rats were more negatively skewed than for aged rats $\left(p<10^{-5}\right.$, Wilcoxon Rank Sum, mean skewness young $=-0.11, n=$ session; aged $=0.33$, $n=113$ sessions).

\section{Ripple frequency decreases during postbehavior rest in aged and young animals}

The observation of robust age-associated differences in oscillatory frequency motivated a further investigation of the time course of this effect. To assess this, we measured ripple frequency in 1 min intervals during prebehavior and postbehavior rest. Results from this analysis indicated a clear decline in both young and aged animals during postbehavior rest (Fig. $3 B, D$ ). The decline is more evident when between-session variation in mean ripple rates is standardized via $Z$ scores (Fig. 3D; Pearson's $\left.r_{\text {young }}=-0.29, r_{\text {aged }}=-0.35\right)$. Although the median ripple frequencies differed between young and aged rats, no difference was observed in the slope of frequency decline across the course of postbehavior sleep ( $t$ test, $p>0.05$ ), indicating that the rate of frequency decline observed during postbehavior rest was similar for both aged and young animals.

\section{No age-associated difference in ripple duration}

Given the observation that ripple oscillatory frequency is lower in aged animals, it is conceivable that the duration of ripples in aged rats is longer to ensure that the number of cycles per ripple remains constant across age. Analysis and comparison of ripple duration, however, revealed no age-associated difference $(p=$ 0.72 , Wilcoxon Rank Sum test, mean young $=52.2 \mathrm{~ms}$, mean aged $=51.8 \mathrm{~ms}, n$ sessions young $=156, n$ sessions aged $=113$ ).

\section{Rate of ripple occurrence is reduced in aged rats}

The rate of ripple occurrence during rest increases following a new learning experience (Eschenko et al., 2008). As the reduced frequency could have cumulative effects over the course of sleep, we investigated the hypothesis that the rate of occurrence of ripple events during rest (ripple density) is altered in aged animals. Rate of occurrence was measured as the number of ripple events for each 5 min window following the start of prebehavior or postbehavior rest. Aged rats expressed a significantly reduced rate of ripple events during postbehavior but not prebehavior rest (Fig. 4A; prebehavior rest: $p>0.05$; two-factor ANOVA, age, time; Fig. $4 B ; p<10^{-4} ; \omega^{2}=0.03 ; n=156$ sessions young, $n=$ 113 sessions old). It is conceivable that the reduced rate of ripple events in aged animals was due to a decrease in sleep quality, as has been documented (for review, see Bliwise, 1993). To address this, measures of movement and depth of slow-wave modulation (see Materials and Methods) were analyzed in aged and young rats. However, we observed that aged animals actually exhibited 

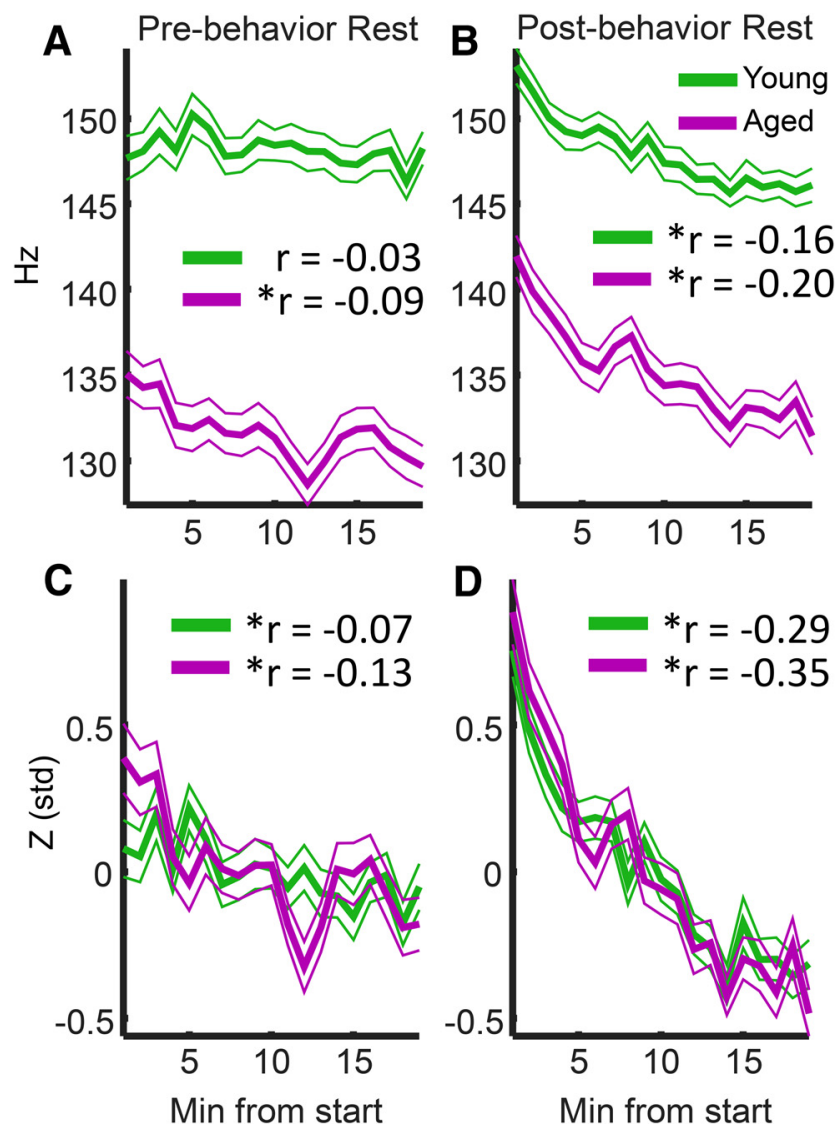

Figure 3. Ripple frequency decreases throughout rest in both age groups. $\boldsymbol{A}$, Peak ripple frequency remained relatively stable during the first $20 \mathrm{~min}$ of prebehavior rest ( $n$ young $=$ $156, n$ aged $=113$ sessions). ${ }^{*} p<0.05$, significant regression. $\boldsymbol{B}$, A decline in frequency was observed during postbehavior rest in aged and young rats. C, D, To control for session-to-session shifts in frequency, all within-session plots were $Z$ score normalized across time. All regression slopes were significant at $p<10^{-4}$, and slopes were not different between aged and young animals ( $t$ test, $p>0.05$ ).

significantly less movement during prebehavior and postbehavior rest relative to young animals (Fig. 4C,D; $p<10^{-4}$; two-factor ANOVA, age, time). Moreover, analysis of the physiological quality of slow-wave sleep $(\theta / \delta$ ratio of local field activity measured during nonmovement periods) (Wierzynski et al., $2009)$ revealed that aged animals had a lower $\theta / \delta$ ratio during postbehavior but not prebehavior rest $\left(p<10^{-4}\right.$, KruskalWallis test, post hoc test $\left.p_{\text {pre }}=0.57, p_{\text {post }}=0.03\right)$. These observations indicate that the reduced ripple rate of occurrence and frequency observed in aged animals is not due to reduced sleep quality.

\section{Ripple-triggered firing rates are similar in young and aged animals}

To begin our investigation into how age-related differences in ripple features related to single-unit activity, firing responses of principal cells and interneurons were aligned to the onset of highfrequency events and the ripple-triggered responses were analyzed. Analysis of firing activity surrounding ripple oscillations, defined as all oscillations $\geq 90 \mathrm{~Hz}$, indicated that principal cells and interneurons in aged and young animals exhibit similar changes in firing rate during ripple events (Fig. $5 A$ ). Two-way ANOVA (factors: age and time interval) of the log-normalized firing activity of principal cells (Buzsáki and Mizuseki, 2014) for the interval preceding ( -400 to $-200 \mathrm{~ms}$ before ripple onset),
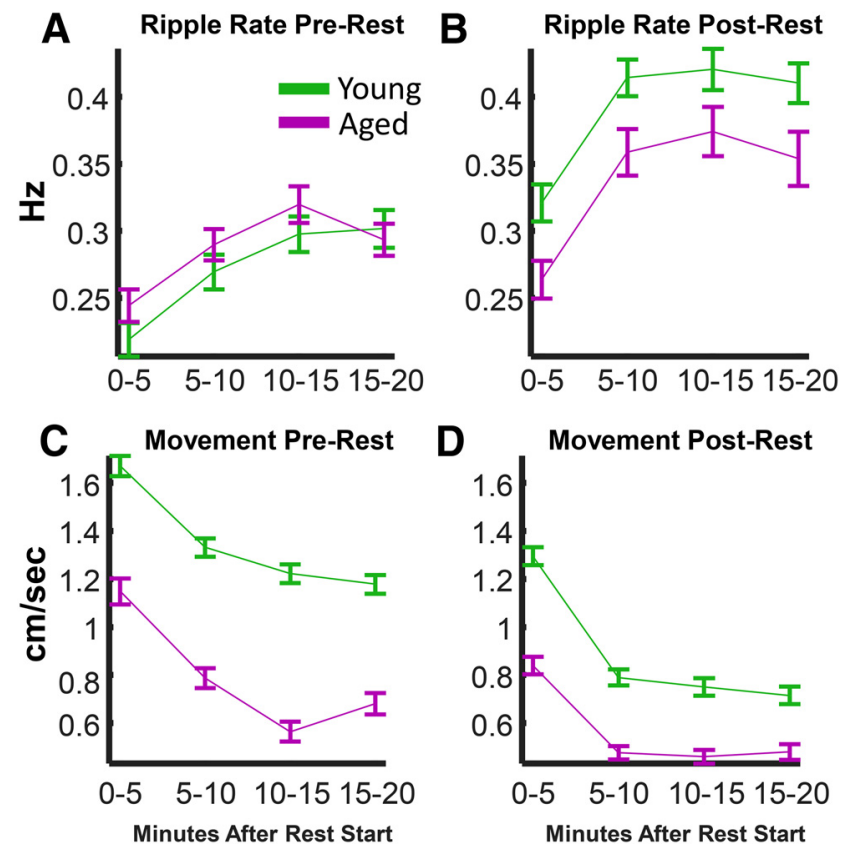

Figure 4. Ripple rate of occurrence was higher during postbehavior rest, and overall movement during rest epochs was greater in young rats. $A$, Ripple rate following the onset of the prerest period. A main effect was observed for time $\left(p<10^{-4}\right.$, ANOVA, $\left.\omega^{2}=0.03\right)$, but not age $(p>0.10)$. $B$, Young animals expressed a higher ripple rate during postbehavior rest $(p<$ $10^{-4}$, ANOVA, effect of age $\left.\omega^{2}=0.02\right)$. C, D, Movement in aged and young rats decreased following rest onset during prebehavior $(\boldsymbol{C})$ and postbehavior $(\boldsymbol{D})$ periods. Young rats showed a higher degree of movement during prebehavior and postbehavior rest than did aged rats ( $p<$ $10^{-4}$, ANOVA. pre age $\omega^{2}=0.19$, post age $\omega^{2}=0.10$ ). Error bars indicate SEM.

during, and after (200-400 ms following ripple offset) revealed a small main effect of age $\left(p<10^{-5}, \omega^{2}=0.001, n\right.$ young $=3900$, $n$ old $=1787$ neurons). Post hoc analysis revealed no age difference in the firing rates of principal cells in aged rats during the ripple oscillation or during inter-ripple periods $(p>0.05$, Tukey-Kramer post hoc test); however, a small significant difference in rate $(\sim 0.06 \mathrm{~Hz})$ was observed in periods before and after the ripple (Fig. $5 B ; p<0.05$, Tukey-Kramer post hoc test). A small but significant increase in firing rate occurred following ripples in both aged and young rats (Fig. $5 C ; p<10^{-6}, t$ test). The same set of analyses was performed with interneurons (Fig. 5D-F; $n$ young $=431, n$ old $=142)$. No main effect of age was observed (ANOVA, $p=0.44$ ). To summarize, although firing rates differed slightly before and after the ripple, ripple-triggered activity in principal cells and interneurons was largely similar in aged and young animals.

Inter-ripple variation in firing activity is reduced in aged rats Despite raw firing rates being relatively similar, it is conceivable that physiological changes associated with aging result in alterations in the variance and precision of neuronal responses. For example, reduced variability in a neuron's response from ripple to ripple would suggest that these neurons explored fewer unique states during rest. On the other hand, increased variance in spiketiming at short intervals $(<50 \mathrm{~ms})$ could reflect noninformation bearing "noise" in the activities of CA1 neurons (e.g., due to synaptic noise). The potential effects of age on these two different forms of variability were examined. In this section, variability in firing rate from ripple to ripple was investigated by calculating the Fano factor (variance/mean) for the vector of spike counts created by counting the number of spikes occurring within each 

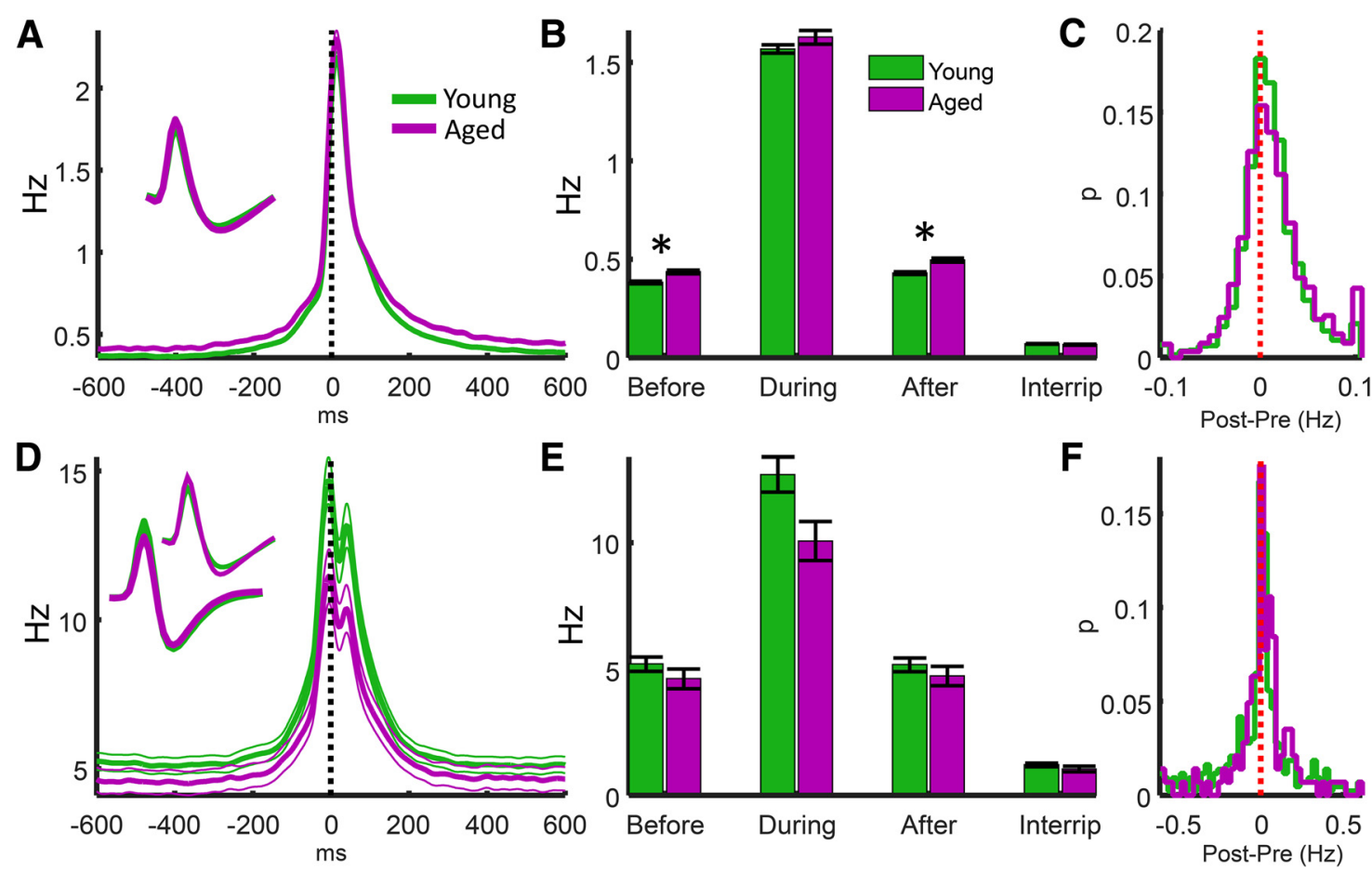

Figure 5. Responses of principal cells and interneurons in aged and young rats. $A$, Average of the perievent responses of principal cells to the onset of ripple oscillations. For each neuron, the mean response to the ripple oscillation was averaged (neurons: $n$ young $=3900, n$ old $=1787$ ). Inset, Average waveform of principal cells. $\boldsymbol{B}$, Mean firing rate and SEM for the -400 to $-200 \mathrm{~ms}$ interval before ripple onset, during the ripple, the $200-400 \mathrm{~ms}$ window after ripple offset, and inter-ripple periods. Two-way ANOVA (age and interval) indicated a main effect of interval ( $p<10^{-7}$ ) and a small main effect of age $\left(p<10^{-5}, \omega^{2}=0.001\right) .{ }^{*} p<0.05$, age-related differences (Tukey-Kramer post hoc test). $\boldsymbol{C}$, The difference in firing rate before and after the oscillation was significantly shifted to the right for young $\left(p<10^{-6}, t\right.$ test) and aged rats $\left(p<10^{-5}, t\right.$ test), indicating an increase in firing rate following ripple oscillations. $\boldsymbol{D}$, Perievent average response of interneurons to ripple oscillations ( $n$ young $=431, n$ old $=142$ ). $E$, Mean firing rate and SEM for interneurons as described for principal cells in $B$. Two-way ANOVA (age and interval) indicated a main effect of interval $\left(p<10^{-7}\right)$ and no effect of age $(p=0.44)$. $\boldsymbol{F}$, There was no difference in interneuron firing rate before and after the oscillation $(p>0.16, t$ test).

ripple event for each age group. Calculated this way, the Fano factor quantifies how reliably a given neuron fires from ripple to ripple.

Analysis of the Fano factor revealed a clear effect of age in both principal cells and interneurons for the preripple, during, and postripple intervals (Fig. 6; Principal cells: two-way ANOVA, factors: age, interval, $p_{\text {interval }}<10^{-10}, \omega^{2}=0.02, p_{\text {age }}<10^{-10}, n$ young $=3900, n$ old $=1787$; Interneurons: main effect of age, $\left(p<10^{-10}\right.$; and interval, $p<10^{-7} ; n$ interneurons young $=$ $431, n$ old $=142$ ). For both principal cells and interneurons, there was a significant reduction in the Fano factor, regardless of age, during the ripple relative to preripple and postripple periods $\left(p<10^{-4}\right.$, Tukey-Kramer post hoc test). For principal cells, there was also an increase in the postripple relative to the preripple interval $\left(p<10^{-5}\right)$.

To determine whether the magnitude of the effect was larger in variance or firing rate (Fig. 5), we compared measures of effect magnitude (Cohen's d). The effect sizes for age-related changes in variability (Fano factor; Fig. 6) were at least twice as large as effect sizes measured between age groups for firing rate (Fig. 7). This indicates that age exerts a greater impact on Fano factor than it does on firing rate, suggesting that aging exerts a stronger impact on ripple-to-ripple measures of neuronal variability than firing rate or activity.

Age-related differences in variance of interspike interval timing in principal cells and interneurons

Small changes in the precision of spike timing can have significant consequences for spike-timing-dependent plasticity ( $\mathrm{Bi}$ and Poo, 1998) and information transfer (Abeles, 1982). Al- though age-associated effects of spike timing have been identified during sleep (Smith et al., 2000), it is unknown how age impacts timing within ripple events. To investigate this, the vector of ISIs was determined for each neuron, and the distribution of these intervals was examined. Analysis was restricted to ISIs that occurred during ripple events. Furthermore, neurons with $<20$ action potentials during rest were eliminated from the analysis. Mean ISI distributions were created by averaging across principal cells and interneurons in aged and young rats (Fig. 8).

Analysis of the distribution of ISIs of principal cells in aged and young animals revealed clear peaks between 3 and $9 \mathrm{~ms}$ (intervals of 333 and $111 \mathrm{~Hz}$, respectively) (Fig. 8A). The mean values of these two distributions were significantly different at multiple points between 3 and $9 \mathrm{~ms}$ ( $p<0.05$, ANOVA, TukeyKramer post hoc test). ANOVA of ISIs for intervals $<10 \mathrm{~ms}$ revealed that ISIs for aged animals were more variable than in young animals (Fig. $8 A$, inset; $t$ test; $p<10^{-10}, n$ young $=2714$, $n$ aged $=994)$. Furthermore, the magnitude of bursting of principal cells, as determined by measuring variability between adjacent interspike intervals (Local Variance) (Shinomoto et al., 2009), revealed that bursting strength was lower in aged animals (mean local variance young $=1.1$, mean aged $=$ $0.9, p<0.001, t$ test $)$.

The observed increase in ISI variance in individual principal cells of aged animals could negatively impact the strength of functional connections between neurons by reducing covariation of spiking between neurons. This hypothesis was explored by examining the peaks of CCs of principal cells during ripple events (see Materials and Methods). Correlation strength was quantified as 

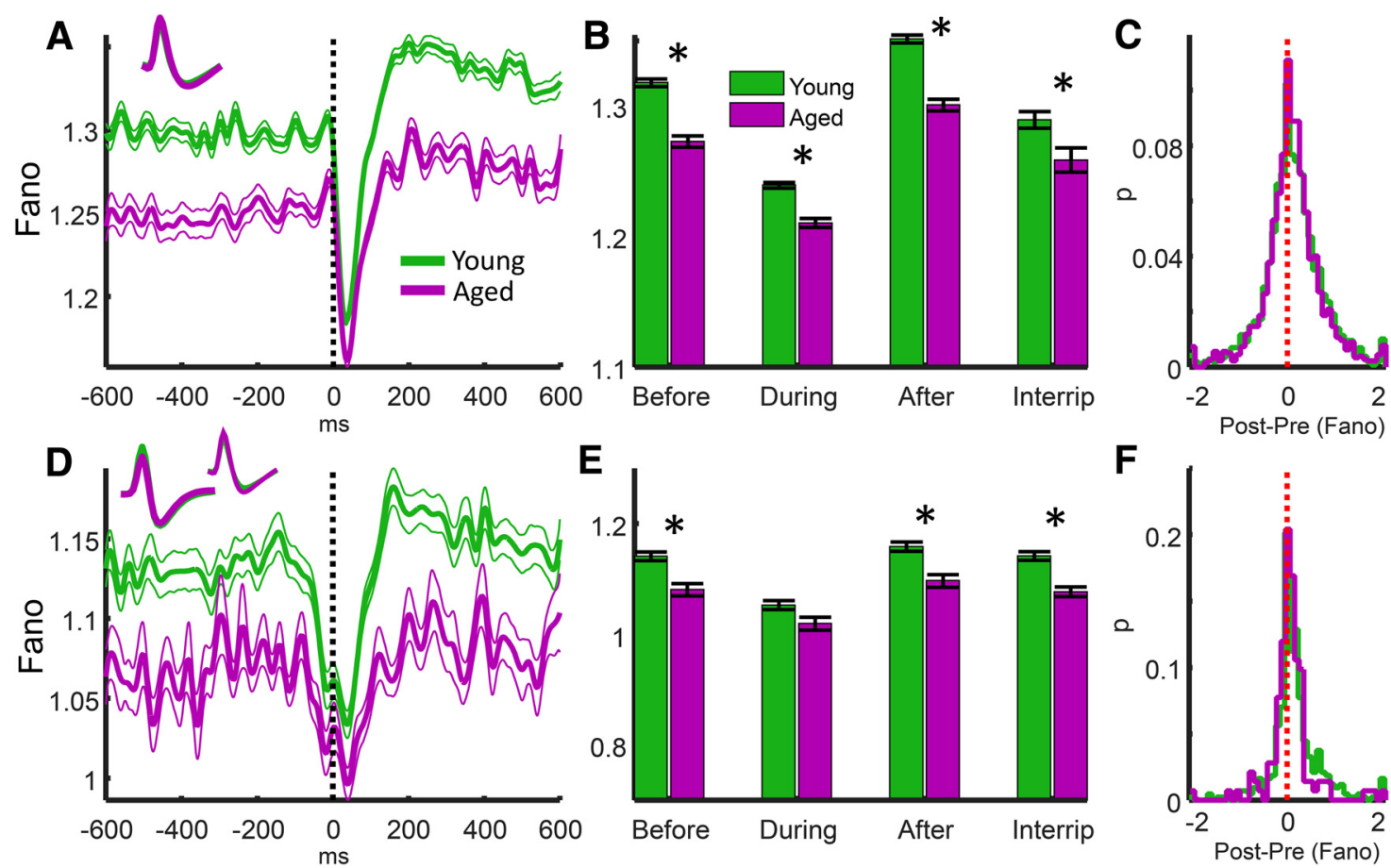

Figure 6. Ripple-to-ripple variability of principal cells and interneurons in aged and young rats. $A$, Perievent measures of variability (Fano factor) of principal cells aligned to the onset of ripple oscillations. For each neuron, the Fano factor was averaged ( $n$ young $=3900, n$ old $=1787$ neurons). Inset, Average waveform of the principal cells. $\boldsymbol{B}$, Two-way ANOVA (age and interval) indicates a main effect of interval $\left(p_{\text {interval }}<10^{-10}\right)$ and a main effect of age $\left(p_{\text {age }}<10^{-10}, \omega^{2}=0.02\right)$. ${ }^{*} p<0.05$, age-related differences (Tukey-Kramer post hoc test). $C$, To determine whether variance changed following ripple oscillations, the difference in Fano factor before and after the oscillation was averaged across neurons. The distribution of differences was significantly shifted to the right for young $\left(p<10^{-7}, t\right.$ test) and aged rats $\left(p<10^{-7}, t\right.$ test), indicating an increase in variance following ripple oscillations. There was no effect of age ( $p=0.08, t$ test). $\boldsymbol{D}$, Perievent average of the Fano factor for interneurons ( $n$ young $=431, n$ old $=142$ ). $\boldsymbol{E}$, As in $\boldsymbol{B}$. Two-way ANOVA (age and interval) indicated a main effect of interval $\left(p<10^{-7}\right.$ ) and a main effect of age $\left(p<10^{-7}, \omega^{2}=0.03\right)$. $\boldsymbol{F}$, The distribution of differences was not significantly shifted for young or aged rats $(p>0.05, t$ test).

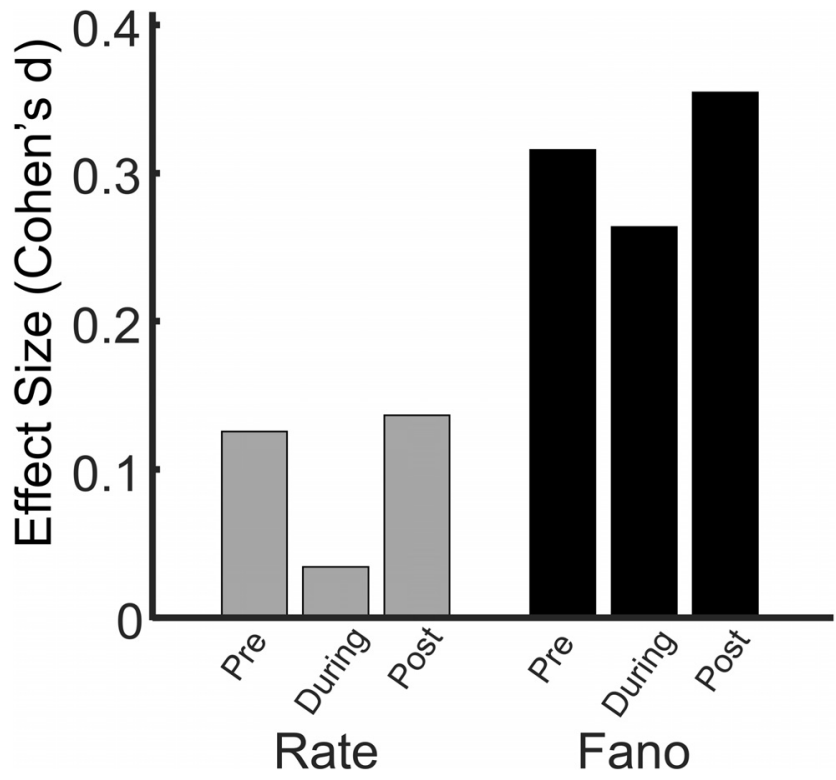

Figure 7. Effect sizes for rate and Fano factor. Larger effect sizes were observed for Fano factor relative to firing rate for principal cells. Comparison of effect sizes (Cohen's $d$ ) between age groups was made for each interval (see Figs. 5B,6B). Cohen's $d$ for Fano factor was at least twice as large for all age comparisons.

the peak height of the cross-correlogram after subtracting an ISI-shuffled control CCs. The peak-aligned CCs for aged and young animals are presented in Figure $8 B$, and analysis of the peak height revealed that the peak was reduced in aged animals
(Fig. $8 B$, inset; $p<0.001, t$ test, $n$ young $=139$ sessions, $n$ aged $=$ 75 sessions, Cohen's $d=0.41$ ).

The analysis of interspike interval variance was also performed on interneurons. In contrast to principal cells, the Fano factor was lower for interneurons in aged rats than in young rats (Fig. $8 C$, inset; $t$ test, $p<0.03$ ). This difference could potentially be explained by the considerable heterogeneity in the types of chemically and functionally distinct interneurons in the hippocampus (Freund and Buzsáki, 1996; Somogyi and Klausberger, 2005). Given that the sample size of interneurons was substantially smaller than principal cells, the difference in effect could be a result of oversampling of a unique subpopulation of interneurons.

Principal cells in aged animals respond to a narrower range of phases of the ripple oscillation

Given our observation that aging alters the precision of the response of neurons to ripple events, we also investigated whether aging alters the precision by which neurons respond to specific phases of the ripple oscillation. Previous reports (Buzsáki et al., 1992) and our own data (Fig. 9A,B) confirm that action potentials of phase-locked principal cells occur near the trough of the ripple oscillation. We also observed that neurons in aged rats fired at later phases (closer to the trough) relative to young animals (Fig. 9C; circular median test; $p<10^{-5}$ ). Examination of the distribution of the preferred phase of each neuron (Fig. $9 B$ ), measured using the circular mean, indicated that principal cells in aged animals were tuned to a more restricted range of phases relative to principal cells in young rats. This was confirmed by calculating the spread of the distribution of preferred phases within each session and then averaging across sessions (Fig. 

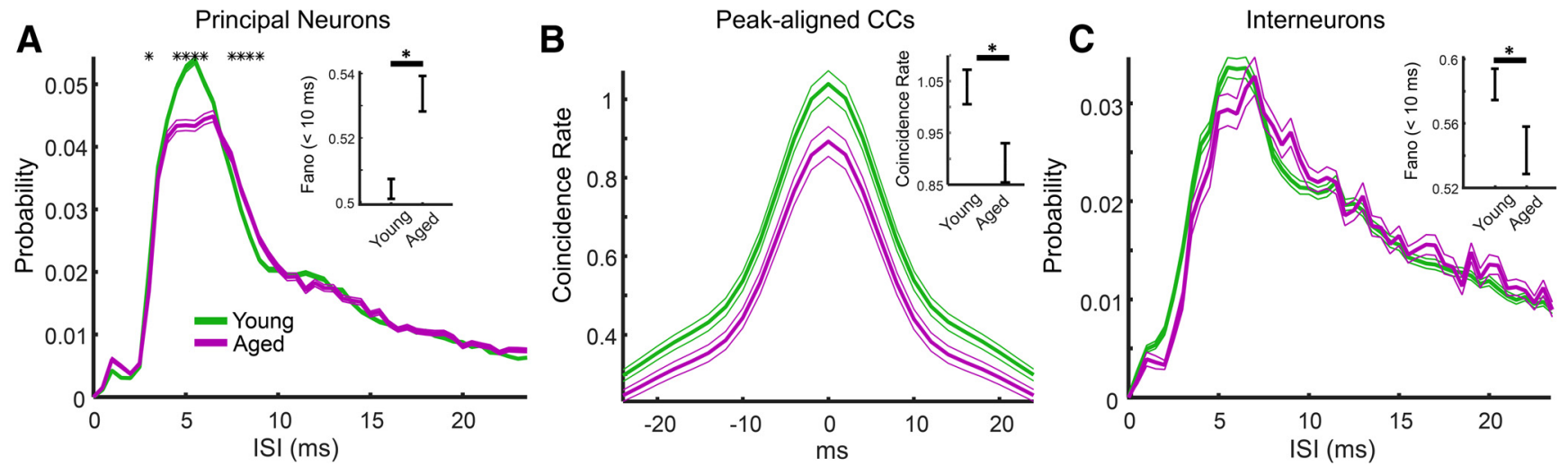

Figure 8. Within-ripple ISI variance is larger and cross-correlation strength is lower in aged animals. $A$, Mean and SEM of ISI histograms for principal cells in aged and young rats ( $n$ young $=2714$, $n$ aged $=994$ ). Before averaging, the ISI histogram for each neuron was normalized by dividing by the total number of observations. ${ }^{*} p<0.05$, points along the $x$-axis that were significantly different (Tukey-Kramer post hoc comparisons). Inset, Variance (Fano factor) in short-latency ISI interval timing $\left(<10 \mathrm{~ms}\right.$ ) was higher in aged rats $\left(t\right.$ test, $\left.p<10^{-6}\right) . \boldsymbol{B}$, The peak coincidence rate between cell pairs was lower in aged animals. For each recording session, all significant CCs were aligned so that the peaks were at zero-lag. These C(s were averaged after subtracting baseline values (see Materials and Methods). Inset, The peak coincidence rate of the C(s was lower in aged animals $(p<0.001, t$ test, $n$ young $=139$ sessions, $n$ aged $=75$ sessions, Cohen's $d=0.41)$. C, Same as in $A$, except for interneurons ( $n$ young $=480, n$ aged $=155$ ). Inset, In contrast to principal cells, the Fano factor was lower for interneurons in aged rats than in young rats $(t$ test, $p<0.03)$.

A
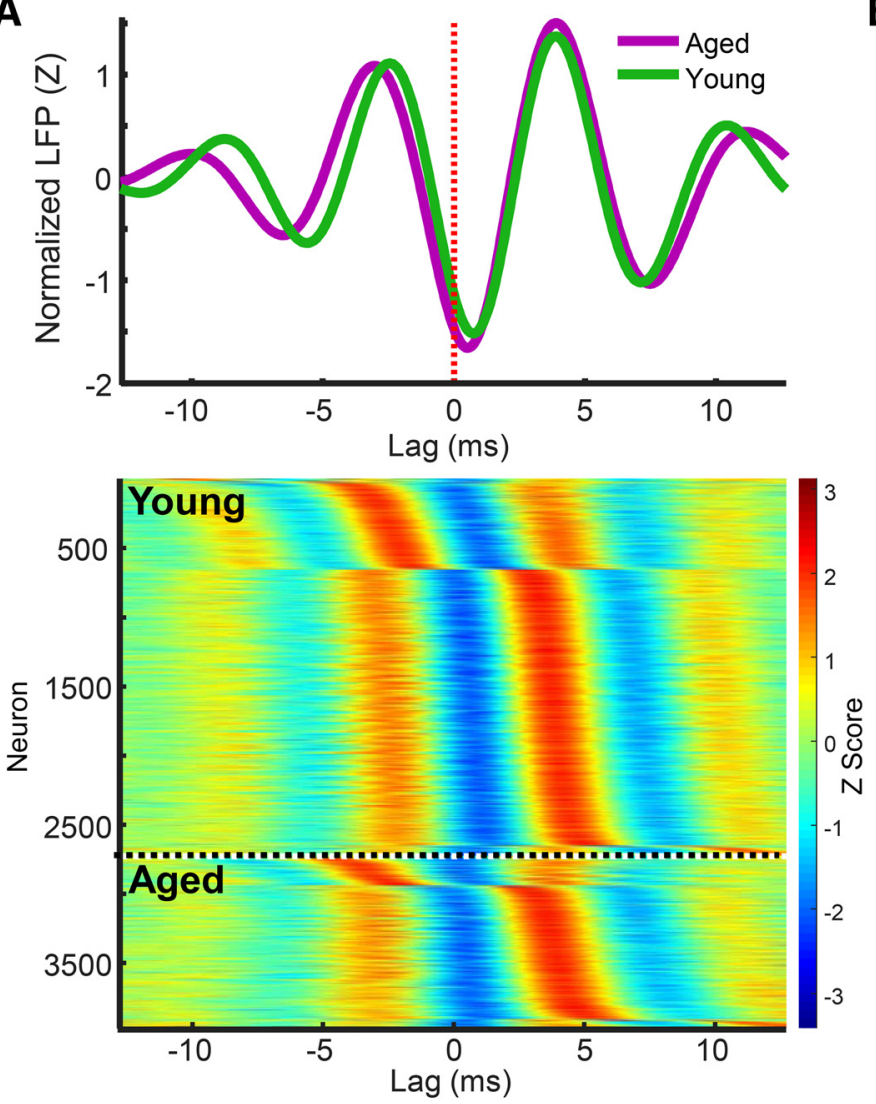
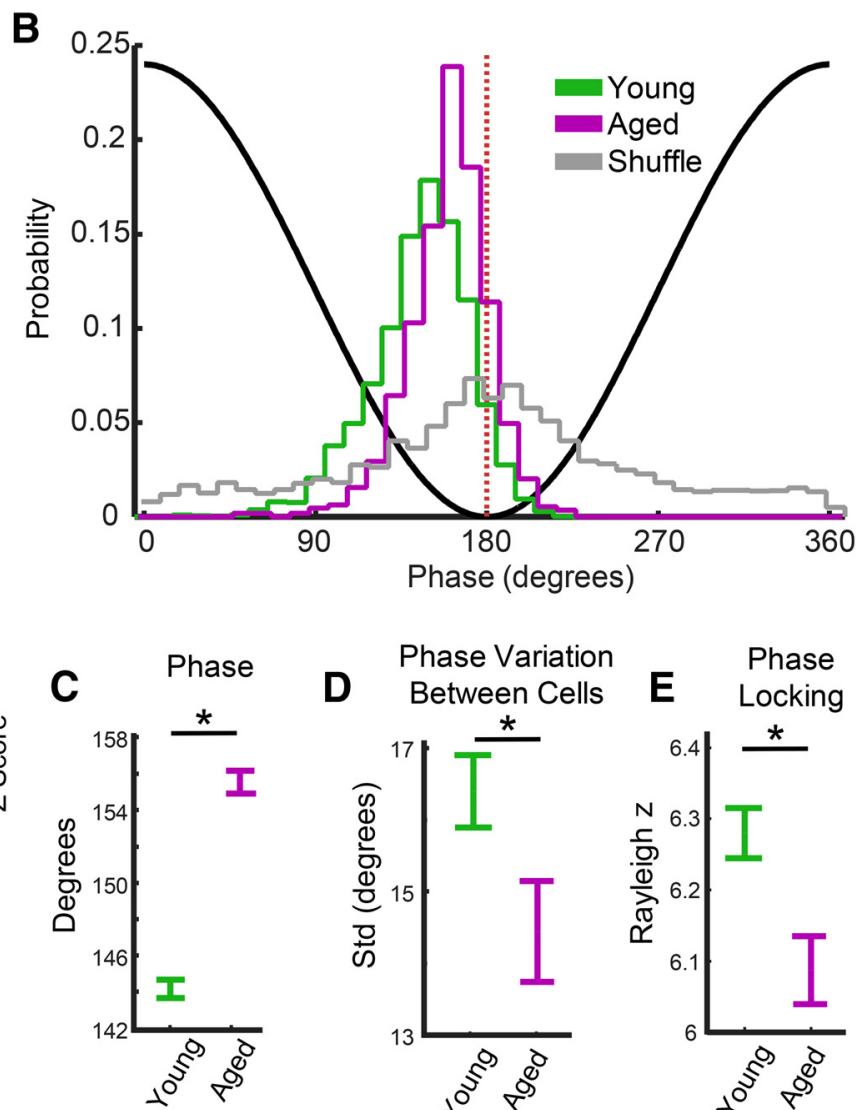

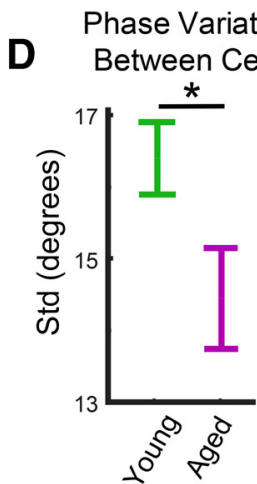

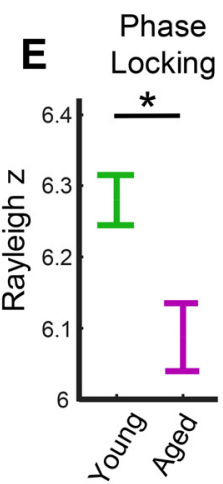

Figure 9. Principal cells in aged rats respond to a narrower range of phases of the ripple oscillation and are active closer to the trough of the oscillation. $A$, Top, Mean spike-triggered average of the local field potential signals (principal cells only). Spikes were restricted to ripple events. During ripple oscillations, spikes tended to occur near the trough and on the falling phase of the oscillation. Color plot presents the spike-triggered averages of every neuron ( $n$ young $=2727, n$ aged $=1245$ ) that was used to compute the two mean traces presented in the top plot. Traces were sorted by peak location. $\boldsymbol{B}$, Distribution of preferred firing phase of principal cells to the ripple oscillation ( $n$ young $=2727, n$ aged $=1245$ ). Black line indicates an idealized cycle. Vertical red dashed line indicates the trough of the oscillation. $C$, Neurons in aged rats respond closer to the trough of the oscillation (circular median test; $p<10^{-5}$, Cohen's $d=0.62$ ). $\boldsymbol{D}$, Neurons in young rats responded to a wider range of preferred phases than cells in aged animals. The spread (SD) of preferred phases of principal cells was calculated for each recording session and then averaged across sessions for aged and young rats $\left(p<10^{-3}, n\right.$ sessions young $173, n$ sessions old 111 , Cohen's $d=0.3)$. $\boldsymbol{E}$, The magnitude of phase-locking (Rayleigh's $Z$ ) was reduced in aged compared with young rats $(p<0.05, n$ young $2727, n$ aged 1245 , Cohen's $d=0.08)$.

9D; circular median test, $p<10^{-3}, n$ sessions young $173, n$ sessions old 111). Although neurons in aged rats were tuned to a more limited range of phases, the strength of phase-locking in the aged rats was lower than in young animals. Specifically, the magnitude of phase-locking (measured as Rayleigh $z$ ) was lower in aged rats (Fig. 9E; $p<0.05$, Cohen's $d=0.08, n$ young $2727, n$ aged 1245). This result is consistent with the increased variability of ISIs of principal cells observed in aged rats (Fig. 

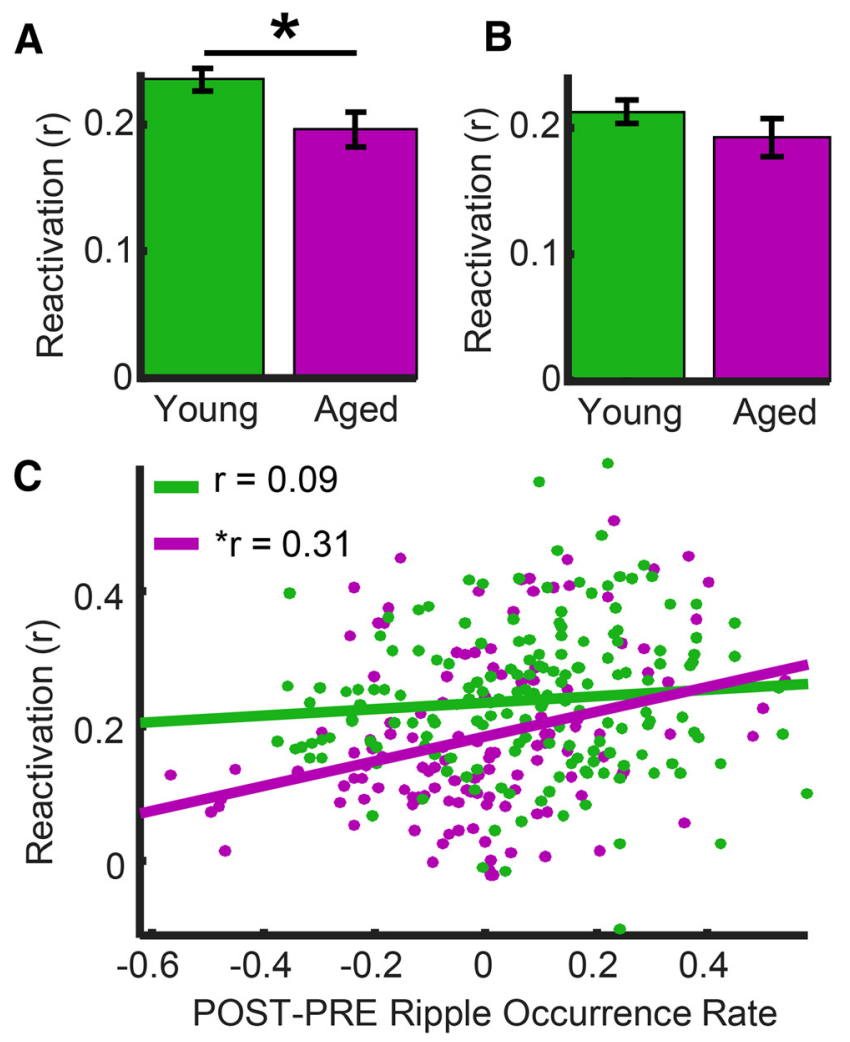

Figure 10. Reduced rate of ripple events in aged animals contributes to reduced reactivation strength. $\boldsymbol{A}$, Cell-pair reactivation was greater in young rats (Cohen's $d=0.33, t$ test, $n=151$ sessions young, $n=85$ sessions aged). ${ }^{*} p<0.001$. $\boldsymbol{B}$, To assess whether this difference could be due to the reduced ripple rate observed in aged rats, the total ripple time per rest epoch was held constant (12 s). Differences between aged and young animals were not significant ( $p=0.16$ ) after imposing this restriction. C, Scatter plot and least-squares regression of the change in ripple occurrence rate from PRE to POST behavior sleep against reactivation strength. A significant positive relationship was observed for aged ( $p<0.001)$ but not young rats $(p=0.09)$. The increase in the ripple occurrence rate in postbehavior sleep was significantly larger in young relative to aged animals ( $p<$ $0.001, t$ test, mean aged $=0.080$, mean young $=-0.009$ ).

8) as measures of phase-locking are reduced by increased variance in interspike timing.

\section{Reduced memory-trace reactivation in aged rats may result from a decrease in ripple events}

The reactivation of patterns of single-unit activity related to recent experience during postbehavior rest are likely to contribute to memory consolidation (Pavlides and Winson, 1989; Wilson and McNaughton, 1994; Born and Wilhelm, 2012). We used the partial correlation measure of reactivation (Kudrimoti et al., 1999) to evaluate the extent to which the pattern of cell-pair correlations identified during behavior is similar to the pattern observed during postbehavior rest (see Materials and Methods). Reactivation was larger in sessions from young rats (Fig. 10A; $p<$ 0.001 , Cohen's $\mathrm{d}=0.33, t$ test, $n=151$ sessions young, $n=85$ sessions aged). To determine whether this difference was due to the reduced rate of occurrence of ripples observed in aged rats (Fig. 4), the analysis was repeated, but the time spent during sleep was held constant. This was accomplished by restricting the analysis to the first $12 \mathrm{~s}$ of accumulated ripple time (this corresponds to $\sim 230$ ripples in each rest epoch for both age groups). This restriction eliminated the age-related difference in reactivation (Fig. 10B; $p=0.16$ ), suggesting that the reduced number of ripple events in aged animals contributes to the decreased level of reactivation.

\section{Discussion}

The main novel findings in the present experiment are that, during rest, the CA1 region of aged rats shows (1) reduced occurrence of ripple events, (2) a $14 \mathrm{~Hz}$ reduction in the frequency of the ripple oscillation itself, and (3) altered patterns of variability and functional connectivity. One consequence of these changes could be to impact the effectiveness of memory consolidation.

\section{Rate of occurrence of ripple events is reduced during postbehavior rest in aged animals}

Aged animals expressed a notable reduction in the rate of occurrence of high-frequency events during postbehavior but not prebehavior rest (Fig. 4). This is the first report of such changes, and these observations complement reports of age-related alterations in neocortical slow waves $(0.8 \mathrm{~Hz})$ and spindles $(12-14 \mathrm{~Hz})$, two oscillatory patterns associated with learning (for review, see Mölle et al., 2009). For example, corticothalamic spindle density, amplitude, and duration are reduced in aged human subjects (Principe and Smith, 1982; Guazzelli et al., 1986; Wei et al., 1999; Nicolas et al., 2001; Crowley et al., 2002). Furthermore, because ripple generation depends on the depolarization of a small number of CA1 pyramidal cells (Stark et al., 2014), the age-related reduction in ripple events may result from the known weaker CA3 input onto CA1 pyramidal cells of aged animals (Barnes et al., 1992). An age-related reduction in the number of ripples in postbehavior but not prebehavior rest is consistent with our observation of weaker reactivation in aged animals (Fig. 10) and with the idea that the number of times a pattern is reactivated is important for the consolidation process.

\section{Ripple frequency is reduced in aged animals}

Aged rats also expressed a notable $14 \mathrm{~Hz}$ reduction in the peak frequency of ripple events relative to young animals (Fig. 2). Two separate studies suggest that the strength of CA3 input onto CA1 pyramidal cells is critical in regulating ripple frequency. First, Sullivan et al., (2011) used simultaneous CA3 and CA1 recordings to determine the correlation between power of CA3 population bursts and the frequency of the resulting high-frequency events in CA1. Their results showed a positive correlation indicating that the stronger CA3 input results in increased CA1 ripple frequency (Sullivan et al., 2011). Second, knockout of CA3 innervation to CA1 in CA3-TeTX mice results in reduced ripple frequency in CA1 and deficits in the consolidation of contextual fear memory (Nakashiba et al., 2009). In the present study, the observed decrease in CA1 ripple frequency may therefore result from the known reduction in functional synaptic innervation of CA1 from CA3 in aging (Barnes et al., 1992).

One possible consequence of the generalized reduction in oscillatory frequency observed in aged animals could be a reduction of the efficacy of STDP (Bi and Poo, 1998). STDP requires that the temporal delay between presynaptic and postsynaptic activation be on the order of 10-15 ms. Because the activity of neurons during ripple oscillations is phase-locked near the trough of the ripple (Buzsáki et al., 1992), a $14 \mathrm{~Hz}$ reduction in frequency from, for example, $146 \mathrm{~Hz}$ (cycle time $=6.8 \mathrm{~ms}$ ) to $132 \mathrm{~Hz}$ (cycle time $=7.6 \mathrm{~ms}$ ) would result in an average increase of $0.8 \mathrm{~ms}$ between spiking events occurring on consecutive cycles. Although this difference may appear to be small, small changes in spike timing can have large effects on plasticity given the exponential decay of the STDP curve. Given the importance of 
multiple short-latency coincident events in the process of memory-trace reactivation (O'Neill et al., 2008), the cumulative impact of reduced plasticity during high-frequency events could significantly affect the reliability of memory stabilization in aging. This idea is at least consistent with our observation of reduced reactivation in aged animals (Fig. 10). Thus, an age-related reduction in ripple occurrence, oscillatory frequency, and increased variability in interspike intervals (Fig. 8) may act synergistically to reduce the efficacy of consolidation.

\section{Differences in phase-coupling to ripple oscillations in aged and young animals}

Hippocampal interneurons and principal cells are most active near the trough of the ripple oscillation (Buzsáki et al., 1992), and individual neurons express tuning to specific phases around the trough (e.g., Fig. 9). The selective response of neurons to the phase of the ripple may facilitate the ordered segmentation of cell assemblies during a sharp-wave ripple event (e.g., Davidson et al., 2009; Wu and Foster, 2014). An age-associated alteration in phase coupling or phase coding could therefore interfere with segregation of cell assemblies during ripple oscillations and impact memory encoding or retrieval. For example, the more limited range of phases in aged animals could indicate a reduced capacity for information encoding and storage.

\section{Normal aging is associated with decreased ripple-to-ripple firing-rate variability and increased short-latency interspike interval variance}

The observation of a narrower distribution of preferred firing phase in aged rats could result from decreased variability in single-unit firing. Such changes could be important given the many ways variability may impact neuronal computation (Buracas et al., 1998; Ermentrout et al., 2008; Faisal et al., 2008; Tiesinga et al., 2008), even if overall mean firing rates are similar in young and old animals, as is the case in CA1 (Fig. 5) (Smith et al., 2000). No experiment, to our knowledge, has studied the impact of normal aging on neuronal variability during ripple events in the hippocampus. We assessed two types of variability: variance in firing rate from ripple to ripple and variance in the interspike interval within a ripple. Analysis of ripple-to-ripple variability revealed that principal cells and interneurons responded more reliably in young animals (Fig. 6). This observation is consistent with the possibility that populations of CA1 neurons activate fewer unique neuronal ensembles in old rats through the course of sleep. With regard to mechanism, the observed reduction in ripple-to-ripple variance could result from physiological changes known to accompany aging. For example, age is associated with an increase in the proportion of silent synapses in CA1 (Barnes et al., 1992). Fewer functional synapses could effectively reduce the range of inputs, and thus reduce the variance of firing activity triggered by CA3.

In our second analysis, we examined the variance of interspike intervals within each ripple event. This analysis revealed that principal cells in aged animals express increased ISI variability for short interspike intervals $<10 \mathrm{~ms}$ (Fig. 8). Neurons in aged animals also had lower burst activity relative to young animals. This contrasts with results from Smith et al. (2000) who reported an increase in burst-activity when bursting was measured as the skewness of the ISI distribution. Possible explanations for this apparent discrepancy are that the Smith et al. (2000) study: (1) did not separate ripple from inter-ripple periods; (2) used different behavioral tasks that did not involve associative learning; and (3) quantified bursting differently; we used the local-variance measure (Shinomoto et al., 2009), and Smith et al. (2000) used the skewness of the ISI distribution.

To investigate the potential impact of increased ISI variance on between-neuron interactions, we analyzed cell-pair crosscorrelations between principal cells in aged and young animals. This analysis revealed that the peak cross-correlation height was lower in aged animals (Fig. $8 B$ ), suggesting that increased ISI variance may contribute to weaker interactions between neurons. These results could be important as alterations in the precision of firing at intervals $<20 \mathrm{~ms}$ could impact spike-timing-dependent plasticity and synaptic integration.

The present results relate to previous investigations of agerelated changes in reactivation during rest. For example, our observation of reduced cross-correlation strength in aged rats could provide an explanation for the age-related reduction in sequence reactivation reported by Gerrard et al. (2008). Specifically, the temporal bias measure used by Gerrard et al. (2008) uses crosscorrelograms to determine whether behavior-associated sequences are preserved during rest. Any decrease in the precision of spike-timing would reduce this measure. In another study, Gerrard et al. (2001) reported reduced reactivation in aged animals when the animals were exposed to novel but not familiar environments. In contrast to this observation, we did identify an age-related reduction in reactivation on a familiar task; however, our task involved a novel spatial-eyeblink associative learning component, whereas the familiar maze used by Gerrard et al. (2001) did not.

In conclusion, our analysis identified multiple features of the ripple oscillation and ripple-associated activity that change with age. An important challenge is determining whether these effects contribute to age-associated memory impairment, or, instead, whether they represent homeostatic processes that help the hippocampus compensate for the myriad physiological changes that accompany normal aging. In this regard, we observed an age-associated reduction in functional connectivity and in memory-trace reactivation. Reductions in correlated activity and reactivation have previously been associated with reduced memory performance on spatial-learning tests (Dupret et al., 2010). Consequently, age-associated declines in spike-timing precision may contribute to memory decline. The existing literature is less clear regarding the specific role of features, such as spike-phase coupling and Fano factor on learning and memory, but the data presented here suggest promising new avenues for investigating how aging alters network computations.

\section{References}

Abeles M (1982) Role of the cortical neuron: integrator or coincidence detector? Isr J Med Sci 18:83-92. Medline

Barnes CA, Rao G, Foster TC, McNaughton BL (1992) Region-specific age effects on AMPA sensitivity: electrophysiological evidence for loss of synaptic contacts in hippocampal field CA1. Hippocampus 2:457-468. CrossRef Medline

Barnes CA, Rao G, McNaughton BL (1996) Functional integrity of NMDAdependent LTP induction mechanisms across the lifespan of F-344 rats. Learn Mem 3:124-137. CrossRef Medline

Barthó P, Hirase H, Monconduit L, Zugaro M, Harris KD, Buzsáki G (2004) Characterization of neocortical principal cells and interneurons by network interactions and extracellular features. J Neurophysiol 92:600-608. CrossRef Medline

Bi GQ, Poo MM (1998) Synaptic modifications in cultured hippocampal neurons: dependence on spike timing, synaptic strength, and postsynaptic cell type. J Neurosci 18:10464-10472. Medline

Bliwise DL (1993) Sleep in normal aging and dementia. Sleep 16:40-81. Medline

Born J, Wilhelm I (2012) System consolidation of memory during sleep. Psychol Res 76:192-203. CrossRef Medline 
Buracas GT, Zador AM, DeWeese MR, Albright TD (1998) Efficient discrimination of temporal patterns by motion-sensitive neurons in primate visual cortex. Neuron 20:959-969. CrossRef Medline

Buzsáki G, Mizuseki K (2014) The log-dynamic brain: how skewed distributions affect network operations. Nat Rev Neurosci 15:264-278. CrossRef Medline

Buzsáki G, Horváth Z, Urioste R, Hetke J, Wise K (1992) High-frequency network oscillation in the hippocampus. Science 256:1025-1027. CrossRef Medline

Cowen SL, McNaughton BL (2007) Selective delay activity in the medial prefrontal cortex of the rat: contribution of sensorimotor information and contingency. J Neurophysiol 98:303-316. CrossRef Medline

Crowley K, Trinder J, Colrain IM (2002) An examination of evoked $\mathrm{K}$-complex amplitude and frequency of occurrence in the elderly. J Sleep Res 11:129-140. CrossRef Medline

Csicsvari J, Hirase H, Czurkó A, Mamiya A, Buzsáki G (1999) Oscillatory coupling of hippocampal pyramidal cells and interneurons in the behaving rat. J Neurosci 19:274-287. Medline

Davidson TJ, Kloosterman F, Wilson MA (2009) Hippocampal replay of extended experience. Neuron 63:497-507. CrossRef Medline

Dupret D, O'Neill J, Pleydell-Bouverie B, Csicsvari J (2010) The reorganization and reactivation of hippocampal maps predict spatial memory performance. Nat Neurosci 13:995-1002. CrossRef Medline

Ego-Stengel V, Wilson MA (2010) Disruption of ripple-associated hippocampal activity during rest impairs spatial learning in the rat. Hippocampus 20:1-10. CrossRef Medline

Ermentrout GB, Galán RF, Urban NN (2008) Reliability, synchrony and noise. Trends Neurosci 31:428-434. CrossRef Medline

Eschenko O, Ramadan W, Mölle M, Born J, Sara SJ (2008) Sustained increase in hippocampal sharp-wave ripple activity during slow-wave sleep after learning. Learn Mem 15:222-228. CrossRef Medline

Faisal AA, Selen LP, Wolpert DM (2008) Noise in the nervous system. Nat Rev Neurosci 9:292-303. CrossRef Medline

Fisher NI (1995) Statistical analysis of circular data. Cambridge, MA: Cambridge UP.

Freund TF, Buzsáki G (1996) Interneurons of the hippocampus. Hippocampus 6:347-470. Medline

Gerrard JL, Kudrimoti H, McNaughton BL, Barnes CA (2001) Reactivation of hippocampal ensemble activity patterns in the aging rat. Behav Neurosci 115:1180-1192. CrossRef Medline

Gerrard JL, Burke SN, McNaughton BL, Barnes CA (2008) Sequence reactivation in the hippocampus is impaired in aged rats. J Neurosci 28: 7883-7890. CrossRef Medline

Girardeau G, Benchenane K, Wiener SI, Buzsáki G, Zugaro MB (2009) Selective suppression of hippocampal ripples impairs spatial memory. Nat Neurosci 12:1222-1223. CrossRef Medline

Girardeau G, Cei A, Zugaro M (2014) Learning-induced plasticity regulates hippocampal sharp-wave ripple drive. J Neurosci 34:5176-5183. CrossRef Medline

Guazzelli M, Feinberg I, Aminoff M, Fein G, Floyd TC, Maggini C (1986) Sleep spindles in normal elderly: comparison with young adult patterns and relation to nocturnal awakening, cognitive function and brain atrophy. Electroencephalogr Clin Neurophysiol 63:526-539. CrossRef Medline

Kanak DJ, Rose GM, Zaveri HP, Patrylo PR (2013) Altered network timing in the CA3-CA1 circuit of hippocampal slices from aged mice. PLoS One 8:e61364. CrossRef Medline

Kudrimoti HS, Barnes CA, McNaughton BL (1999) Reactivation of hippocampal cell assemblies: effects of behavioral state, experience, and EEG dynamics. J Neurosci 19:4090-4101. Medline

Marr D (1971) Simple memory: a theory for archicortex. Philos Trans R Soc Lond B Biol Sci 262:23-81. CrossRef Medline

McClelland JL, McNaughton BL, O’Reilly RC (1995) Why there are complementary learning systems in the hippocampus and neocortex: insights from the successes and failures of connectionist models of learning and memory. Psychol Rev 102:419-457. CrossRef Medline

Mölle M, Eschenko O, Gais S, Sara SJ, Born J (2009) The influence of learning on sleep slow oscillations and associated spindles and ripples in humans and rats. Eur J Neurosci 29:1071-1081. CrossRef Medline

Morris R (1984) Developments of a water-maze procedure for studying spatial learning in the rat. J Neurosci Methods 11:47-60. CrossRef Medline
Nakashiba T, Buhl DL, McHugh TJ, Tonegawa S (2009) Hippocampal CA3 output is crucial for ripple-associated reactivation and consolidation of memory. Neuron 62:781-787. CrossRef Medline

Nicolas A, Petit D, Rompré S, Montplaisir J (2001) Sleep spindle characteristics in healthy subjects of different age groups. Clin Neurophysiol 112: 521-527. CrossRef Medline

Nokia M, Penttonen M, Wikgren J (2010) Hippocampal ripple-contingent training accelerates trace eyeblink conditioning and retards extinction in rabbits. J Neurosci Off J Soc Neurosci 30:11486-11492. CrossRef Medline

O'Keefe J, Nadel L (1978) The hippocampus as a cognitive map. Oxford, MA: Clarendon.

O’Neill J, Senior TJ, Allen K, Huxter JR, Csicsvari J (2008) Reactivation of experience-dependent cell assembly patterns in the hippocampus. Nat Neurosci 11:209-215. CrossRef Medline

Pace-Schott EF, Spencer RM (2015) Sleep-dependent memory consolidation in healthy aging and mild cognitive impairment. Curr Top Behav Neurosci 25:307-330. CrossRef Medline

Pavlides C, Winson J (1989) Influences of hippocampal place cell firing in the awake state on the activity of these cells during subsequent sleep episodes. J Neurosci 9:2907-2918. Medline

Pennartz CM, Lee E, Verheul J, Lipa P, Barnes CA, McNaughton BL (2004) The ventral striatum in off-line processing: ensemble reactivation during sleep and modulation by hippocampal ripples. J Neurosci 24:6446-6456. CrossRef Medline

Principe JC, Smith JR (1982) Sleep spindle characteristics as a function of age. Sleep 5:73-84. Medline

Ray S, Maunsell JH (2011) Different origins of gamma rhythm and highgamma activity in macaque visual cortex. PLoS Biol 9:e1000610. CrossRef Medline

Schimanski LA, Lipa P, Barnes CA (2013) Tracking the course of hippocampal representations during learning: when is the map required? J Neurosci 33:3094-3106. CrossRef Medline

Shinomoto S, Kim H, Shimokawa T, Matsuno N, Funahashi S, Shima K, Fujita I, Tamura H, Doi T, Kawano K, Inaba N, Fukushima K, Kurkin S, Kurata K, Taira M, Tsutsui K, Komatsu H, Ogawa T, Koida K, Tanji J, et al. (2009) Relating neuronal firing patterns to functional differentiation of cerebral cortex. PLoS Comput Biol 5:e1000433. CrossRef Medline

Smith AC, Gerrard JL, Barnes CA, McNaughton BL (2000) Effect of age on burst firing characteristics of rat hippocampal pyramidal cells. Neuroreport 11:3865-3871. CrossRef Medline

Somogyi P, Klausberger T (2005) Defined types of cortical interneurone structure space and spike timing in the hippocampus. J Physiol 562:9-26. CrossRef Medline

Stark E, Roux L, Eichler R, Senzai Y, Royer S, Buzsáki G (2014) Pyramidal cell-interneuron interactions underlie hippocampal ripple oscillations. Neuron 83:467-480. CrossRef Medline

Sullivan D, Csicsvari J, Mizuseki K, Montgomery S, Diba K, Buzsáki G (2011) Relationships between hippocampal sharp waves, ripples, and fast gamma oscillation: influence of dentate and entorhinal cortical activity. J Neurosci 31:8605-8616. CrossRef Medline

Tiesinga P, Fellous JM, Sejnowski TJ (2008) Regulation of spike timing in visual cortical circuits. Nat Rev Neurosci 9:97-107. CrossRef Medline

Wei HG, Riel E, Czeisler CA, Dijk DJ (1999) Attenuated amplitude of circadian and sleep-dependent modulation of electroencephalographic sleep spindle characteristics in elderly human subjects. Neurosci Lett 260: 29-32. CrossRef Medline

Wierzynski CM, Lubenov EV, Gu M, Siapas AG (2009) State-dependent spike-timing relationships between hippocampal and prefrontal circuits during sleep. Neuron 61:587-596. CrossRef Medline

Wilson MA, McNaughton BL (1993) Dynamics of the hippocampal ensemble code for space. Science 261:1055-1058. CrossRef Medline

Wilson MA, McNaughton BL (1994) Reactivation of hippocampal ensemble memories during sleep. Science 265:676-679. CrossRef Medline

Wu X, Foster DJ (2014) Hippocampal replay captures the unique topological structure of a novel environment. J Neurosci 34:6459-6469. CrossRef Medline

Zanos TP, Mineault PJ, Pack CC (2011) Removal of spurious correlations between spikes and local field potentials. J Neurophysiol 105:474-486. CrossRef Medline 